\title{
A EM Geophysical survey over an abandoned coal mining area S Pedro da Cova (North Portugal)
}

\author{
Manuel Senos Matias and Fernando Almeida \\ Department of Geosciences, University of Aveiro, 3800 Aveiro, Portugal.
}

The environmental recovery of former mining areas and communities is an economical activity of increasing importance. Among other aspects such activity must include careful planing and an accurate knowledge of the positioning of old mining works. Frequently these works were conducted underground; very often the location of these works is very difficult because of their complexity as well as lack of information. Thus Geophysics can be very helpful both in their location and in the study of their influence on subsurface geological formations.

S.Pedro da Cova (near the town of Oporto, North Portugal) is an abandoned coal mine that was exploited both by underground methods (open stooping) and open pit until the late seventies. The mine is located in a village with the same name that is an area of increasing development pressure, and the influence of mine works on local buildings is clearly seen by visual inspection.

Nowadays, the former mining company and the local council intend to redevelop part of the mining region and to build a residential area. It is obvious that urbanization planning, that is the location of public gardens and facilities, single houses, multistore residential flats, etc, needs detailed information about local and underground geology, its relations to mining works and the impacts of such works in the area.

The S. Pedro da Cova coal deposit is located along a very important Hercynian shear zone. In broad terms, local geology consists of steeply dipping coal layers occurring in Stephanian formations that form several coal sub basins separated by Silurian rocks. The whole mining area is limited to the West by pre Ordovician formations and to the East by Devonian formations.

Bearing in mind local geology and ground conditions an Electromagnetic Geophysical survey was designed in order to: 
- carry out the geophysical mapping of the area,

- investigate the continuation in depth of surface formations,

- detect the mine works and their eventual influence in the area to be developed, -estimate the thickness of local tailing disposal sites.

Therefore, several EM soundings (Geonics EM34 using both vertical and horizontal coils, and coil separations of 10,20 and 40 metres) were conducted over the tailing disposal sites. Depth interpretation was performed with a commercial interactive computer program. The starting model used in the interpretation was coherent with the reconstructed primitive topography of the sites.

Afterwards, fourteen parallel EM profiles,( with an approximate East-West orientation) were conducted. Profile length was dependent on local conditions, profile separation was 25 metres and measurements interval, on each profile, were 12.5 or 25 metres depending on coil separation. Therefore it was hoped to obtain a $3 \mathrm{D}$ coverage of the area.

Thus, conductivity maps corresponding to different coil separation distances were produced. The maps obtained with shorter distances were interpreted in terms of surface geology. However, with the use of horizontal coils and increasing separation, information from deeper structures can be obtained. Therefore the complete suite of maps must be interpreted in accordance with coil distance and orientation, providing an overall look at the evolution of conductivity, and thus of the geology and/or mine works, with depth.

Using the expected, or theoretical, depth investigation of the different EM34 spacial arrangements several conductivity pseudo-sections were constructed and plotted in accordance with local topographic highs. These pseudo sections were interpreted considering that Stephanian coal formations and fractured, and probably flooded, mine works should show a different and distinct conductivity than that of the Silurian rocks. In fact, a broad agreement was found between the conductivity pseudo sections, the available geological sections and the known position of mine works. 
The use of several parallel conductivity pseudo-sections provided a $3 \mathrm{D}$ image of the area and therefore a better understanding of local geology and structure, enhancing the information obtained from the known geological sections.

Finally, these geological and mining information was passed on to the urban planners and has contributed decisively (to the point that the initial redevelopment planning was altered) to the establishment of a comprehensive development strategy of the area. 
